\title{
THE STRESS RELAXATION OF MODIFIED BITUMENS
}

Pavel Coufalík, Ph.D. Student, coufalik.p@fce.vutbr.cz Brno University of Technology, Faculty of Civil Engineering, Czech Republic

Ondřej Dašek, Ph.D. Student, dasek.o@fce.vutbr.cz Brno University of Technology, Faculty of Civil Engineering, Czech Republic

Jiři Kachtik, Ph.D. Student, kachtik.j@fce.vutbr.cz Brno University of Technology, Faculty of Civil Engineering, Czech Republic

Jan Kudrna, Professor, kudrna.j@fce.vutbr.cz Brno University of Technology, Faculty of Civil Engineering, Czech Republic

Svatopluk Stoklásek,RNDr., stois@volny.cz.Independent consultant, Czech Republic

doi: 10.1515/ijpeat-2015-0004

\begin{abstract}
The Asphalt pavements in Central and Eastern Europe have to be resistant to high and very low temperatures and climatic changes. Especially emphasize influence of low temperatures seems to be critical parameter. That is why the modified bitumens with low temperature susceptibility and with high resistance to low temperature cracking are searched for. Dynamic Shear Rheometer (DSR) can be used as a quick method that can evaluate the modification system of bituminous binders. The advantage of DSR testing is also related to possibility of comparison of unaged and aged bitumen.
\end{abstract}

The relaxations of shear stress of several asphalt rubber binders (containing $11 \%$, $13 \%, 15 \%$ and $17 \%$ of crumb rubber) and paving bitumen were determined in DSR at the temperature of $0{ }^{\circ} \mathrm{C}$ and $-10^{\circ} \mathrm{C}$. Relaxation tests were performed in the controlled strain regime. Total shear strain (rotation of upper geometry) was set to $1 \%$ of the sample thickness and stress was applied for $60 \mathrm{~s}$. Relaxation time was set to a period of 15 minutes. The shear stress relaxation behaviour of unaged bitumens and bitumens aged after 75 minutes and 225 minutes in Rolling Thin Film Oven Test (RTFOT) is presented and discussed.

\section{Introduction}

Bituminous binders in Central and Eastern Europe must resist a wide range of temperatures. In the Czech Republic, the temperature of the pavement surface when lit by the Sun can be as high as $60{ }^{\circ} \mathrm{C}$, while during the winter months can fall even below $-25^{\circ} \mathrm{C}$. High temperatures impose a risk of development of permanent deformations, whereas low temperatures can lead to crack formation. In the recent years, apart from binders modified with polymers, also Crumb Rubber modified Bitumen ( $\mathrm{CRmB}$ or named as asphalt rubbers) are being used, which are quite common in for example the United States, the Republic of South Africa and to a limited extent also in some other European countries (Carlson and Zhu, 1999), (Heitzman, 1992), (Kudrna and Dašek, 2012). 


\section{The Issue of Low Temperature Properties of Bituminous Mixtures and Bituminous Binders}

To evaluate the low temperature properties of bituminous mixtures, the Thermal Stress Restrained Specimen Test (TSRST) according to the EN 12697-46 (2012) is currently being used. During this test, a cuboid-shaped specimen, which length is held constant, is subjected to a controlled temperature decrease with constant temperature rate. Due to the prohibited thermal shrinkage, cryogenic stress is built up in the specimen until failure.

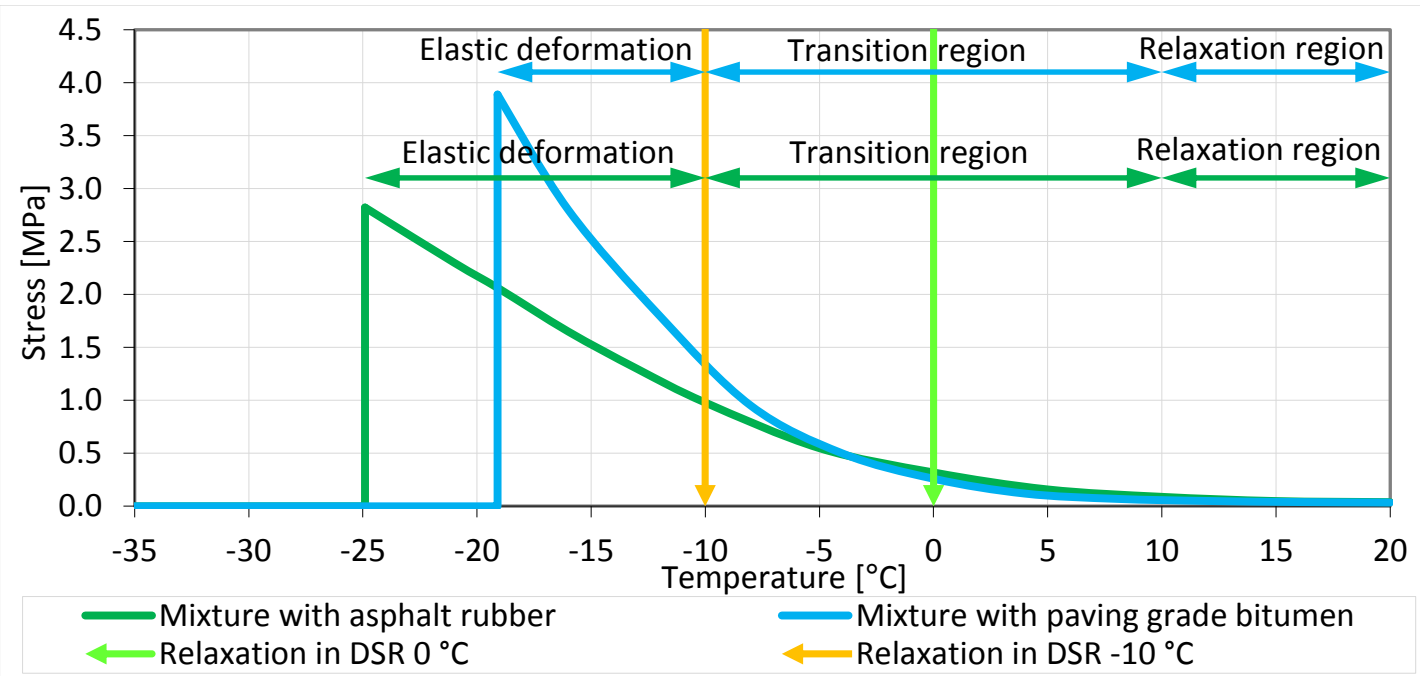

Figure 1. Thermal stress restrained specimen test - the different course of the curves for a mixture with paving bitumen and with $\mathrm{CRmB}$

The assessment of low temperature properties provides information about the critical failure temperature and tensile strength for particular bituminous mixture (Isacsson and Zeng, 1998), (Sebaaly et al., 2001). Figure 1 shows the record of a TSRST test for two different bituminous mixtures, which both use a different bituminous binder. The first mixture contains a paving bitumen, the other one Crumb Rubber modified Bitumen $(\mathrm{CRmB})$. The graph can be used to find the temperature region, at which there is still a complete relaxation of the tensile stress in the tested specimen (tensile stress does not increase as the temperature decreases) and it is also possible to derive a temperature threshold, at which this relaxation is no longer observed (linear relationship between stress and decreasing temperature - elastic behaviour). At higher temperatures (above approximately $10^{\circ} \mathrm{C}$ ), the mixture is able to eliminate the entire stress by stress relaxation, and in the temperature range from about $10{ }^{\circ} \mathrm{C}$ to $-10{ }^{\circ} \mathrm{C}$ there is a transition from the relaxation phase to the linear phase. During the linear phase the mixture is no longer able to relax, behaves elastically and tensile stress increases until it reaches a level, at which a tensile crack forms in the tested specimen.

The TSRST single-axis strain test is time-consuming and the results depend especially on the thickness of the bituminous film, the air void content of the bituminous mixture, aggregate gradation, the type of bituminous binder used etc.

Another method used to assess the suitability of a bituminous mixture is based on Gauer test (Gauer, 1996), which is described in detail in the Technical 
recommendations of the Czech Ministry of Transport TP 151 (2010). The test is based on determining the relaxation characteristics of a particular bituminous mixture using the tensile bending strength test. The test is performed in a water bath at a temperature of $\pm 0{ }^{\circ} \mathrm{C}$. An example of results from a relaxation test of a bituminous mixture is shown in Figure 2. The characteristics of the bituminous mixtures used are given in Table 1. This test is also time-consuming and unable to reliably differentiate between the low temperature characteristics of the individual bituminous mixtures.

Table 1. Various bituminous mixtures used in the relaxation test

\begin{tabular}{|c|c|c|c|c|c|}
\hline \multicolumn{2}{|c|}{ Mixture } & $\begin{array}{c}\text { Binder } \\
\text { content }\end{array}$ & Air void content & $\begin{array}{c}\text { Bituminous film } \\
\text { thickness }\end{array}$ & $\begin{array}{c}\text { Residual stress } \\
\text { in } \mathrm{t}=300 \mathrm{~s}\end{array}$ \\
\hline & & {$[\%]$} & {$[\%]$} & {$\left[10^{3} \mathrm{~mm}\right]$} & {$[\%]$} \\
\hline 1 & SAL 5 & 10,0 & 3,6 & 7.74 & 37,7 \\
\hline 3 & SAL 5 & 10,0 & 6,7 & 10.40 & 39,4 \\
\hline 4 & SAL 5 & 12,0 & 4,1 & 12.76 & 35,7 \\
\hline 5 & SAL 5 & 10,0 & 2,8 & 5.71 & 35,3 \\
\hline 6 & SAL 5 & 10,0 & - & - & 28,9 \\
\hline
\end{tabular}

Note: SAL means Stress Absorbing layer with granularity 5 (8) $\mathrm{mm}$

Because of the reasons outlined above, we were looking for an alternative method, which would easily and also effectively describe and compare low temperature characteristics of various bituminous binders in a lab. We focused on measuring the relaxation of shear stress of bituminous binders in a Dynamic Shear Rheometer (DSR). These tests were preceded by the standard bituminous binder tests.

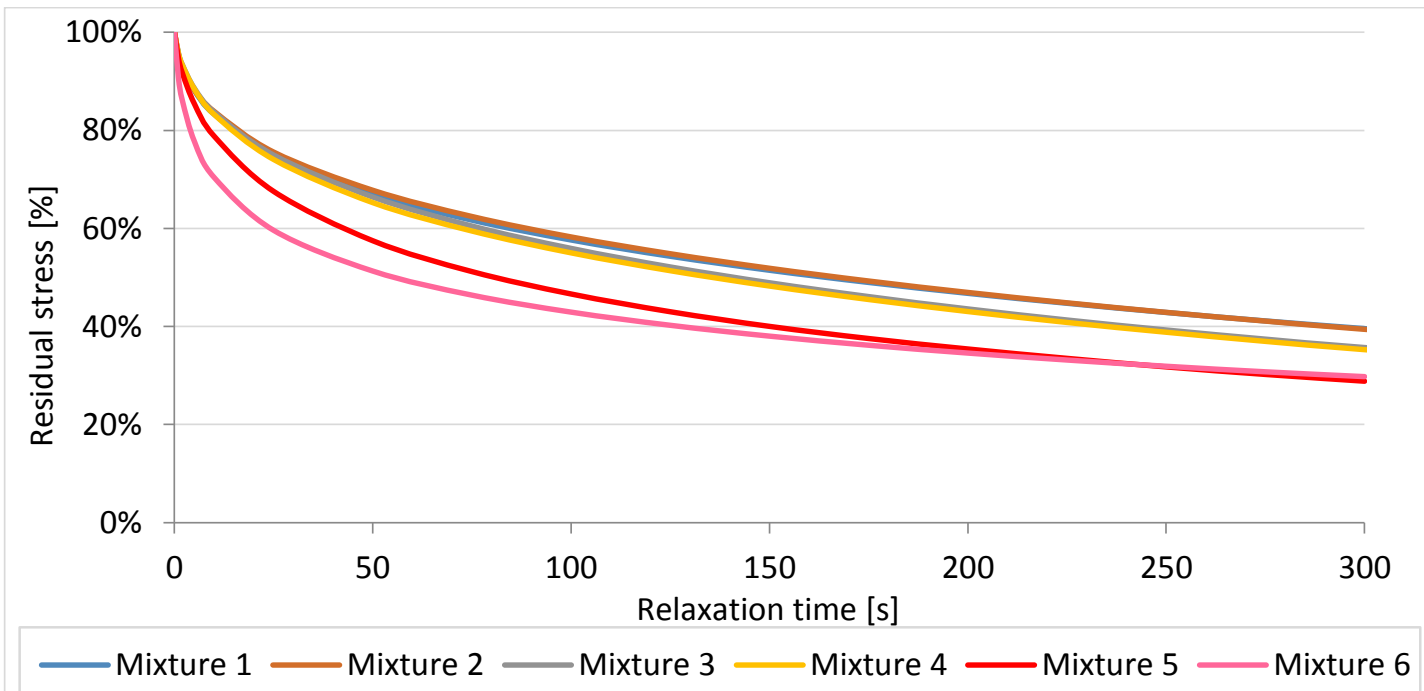

Figure 2. The decrease in strength during the relaxation test of bituminous mixtures

\section{Applied Test Procedures}

The following empirical tests were selected to evaluate the properties of the measured bituminous binders: needle penetration according to the EN 1426 (2007), softening point using the ring and ball method according to the EN 1427 (2007), elastic 
recovery according to the EN 13398 (2010), and penetration and recovery (resilience) according to the EN 13880-3 (2003). At the end, rheological tests were performed in the dynamic shear rheometer (DSR).

Rotational (oscillatory) rheometers (referred to in road engineering as Dynamic Shear Rheometers - DSR) are complex devices designed to characterize rheological behaviour of a wide spectrum of materials. They are used to describe the dynamic viscosity, and also allow measuring other rheological properties in both, the steady shear mode and the oscillatory mode. The main working part of a rotational rheometer consists of two co-axial geometries - a moving one (the rotor) and a static one (the stator) - while the tested material is placed between them. The geometries are used in three basic configurations: cylinder-cylinder, plate-plate, cone-plate, each of them appropriate for particular consistencies of the tested materials and different types of measurements (McGennis et al., 1994). For unusual materials (such as nonhomogenous substances or substances containing larger solid particles), it is possible to use special geometry types - the vane tools (Zalman, 2011).

The tests were performed on the Kinexus rotational rheometer manufactured by the British company Malvern.

\section{Measurement of the Shear Stress Relaxation in DSR}

The measurement of the shear stress relaxation using the DSR can be an indicator, which shows the ability of a material to eliminate the imposed stress and also reflects the quality of the modifying system. The ability of a bituminous mixture to quickly absorb the imposed stress is a significant factor, which affects the ability of the bituminous mixture to resist crack formation. The ability of the bituminous mixture to transfer shear stress depends on the mixture properties, as well as the thickness of the bituminous film.

To determine the rate of shear stress relaxation in DSR, a procedure was used, where first a sample of a bituminous binder is exposed to a shear strain of a given shear rate under a given temperature. The shear strain should be in the linear viscoelastic region. The applied shear strain (rotation of upper geometry) is maintained at a constant level for the course of the entire test. After the initial increase of shear stress, which corresponds to the applied shear strain in applied shear rate, the decrease in stress over time is monitored. The result of the test is a relaxation curve of shear stress, which is the dependency of shear stress decrease on time.

For ideally elastic materials no shear stress relaxation occurs after a shear strain (rotation of upper geometry) is applied and the shear stress remains constant. In the case of a substance with ideally viscous behaviour, upon applying the shear strain, the shear stress is eliminated almost immediately. When shear strain is applied on a viscoelastic material, there is a delayed relaxation of the shear stress - either partial, or after a certain period of time, complete. The relaxation curve has an exponential shape and the degree of shear stress relaxation depends on the viscous component of the material.

When a shear strain (rotation of upper geometry) is applied on a viscoelastic liquid, a complete relaxation of the shear stress is achieved (provided that the relaxation time 
is sufficiently long). In the case of viscoelastic solids, the shear stress relaxation does not reach zero even after a very long time period. The relaxation curve asymptotically approaches a final value, which is referred to as the equilibrium stress. This means that at least parts of the molecules are chemically or physically linked and therefore unable to move freely. It is possible to determine the relaxation module at any moment during the experiment by finding the ratio of the instantaneous shear stress and the initially set shear strain (Mezger, 2011).

Shear stress relaxation in DSR was determined at $0{ }^{\circ} \mathrm{C}$ and $-10{ }^{\circ} \mathrm{C}$ using parallel plates geometry with a diameter of $8 \mathrm{~mm}$ and gap size $2 \mathrm{~mm}$ (Sui et al., 2011). This temperature was chosen with respect to the possible measuring range of the DSR and was derived from the measurements using the TSRST, as shown in Figure 1. Relaxation tests were performed in the controlled strain mode. The target shear strain (rotation of upper geometry) was set to a value of $1 \%$ of the sample thickness and the time for reaching target strain was selected $60 \mathrm{~s}$. Relaxation time was set to 15 minutes.

\section{Laboratory Procedures Modelling Binder Ageing}

One of the most common causes of formation of low temperature cracks is also binder ageing. Accelerated tests are used, which model short-term binder ageing during bituminous mixture production, and long-term ageing occurring on the real road (Brown and Scholz, 2000), (Mturi and O'Connell, 2012).

One of the most commonly used methods, which simulate short-term ageing, is the test of thermal stability in a thin moving layer by Rolling Thin Film Oven Test (RTFOT) according to EN 12607-1 (2007), the test of thermal stability of thin film by Thin Film Oven Test (TFOT) and the test of short-term ageing by Rotating Flask Test (RFT) (Bahia et al., 1998).

To test the long-term binder ageing, the most commonly used test is a test of accelerated long-term ageing in a pressure ageing vessel (PAV) or the Rotating Cylinder Ageing Test (RCAT) (Bahia and Anderson, 1995). It is also possible to use a modified version of the RTFOT, where the test period is tripled in comparison to the standard RTFOT used for short-term ageing. Such RTFOT modification can better differentiate between various binders and its tendency towards thermo-oxidative ageing (Muller and Jenkins, 2011). This 3-times-RTFOT-aging method was also used in our work (Spiegl, 2009).

The effects of heat and air are determined from the change in mass of the bituminous binder in flasks or change in bituminous binder properties, which are determined before and after the ageing process. To determine the changes in properties of the binder it is possible to use the needle penetration test, softening point or for example dynamic viscosity according to EN 13302 (2010). Changes can be described using rheological properties determined by dynamic shear rheometer (DSR). Leakage of highly viscous binder $(\mathrm{CRmB})$ from the flasks was avoided by inserting rolled thin metal plate into flasks not to reduce air flow from the nozzle. 


\section{Materials Used}

In the Czech Republic, the asphalt rubber has been used more and more often in the recent years. It is generally assumed that this type of binder is suitable for stress absorbing layers (SAL). For that reason, CRmBs with different content of crumb rubber have been made, which thereafter undergo a simulation of short-term ageing by the RTFOT according to EN 12607-1 (2007) and long-term ageing by the modified $3 \times$ RTFOT. Using empirical tests and tests performed on the DSR, it is possible to evaluate the effects of the rubber on ageing and on the rate of binder relaxation.

$\mathrm{CRmB}$ was prepared by blending paving bitumen of gradation 50/70 with crumb rubber of grain size $0 / 1 \mathrm{~mm}$ (ambient process) in a laboratory mixer at a temperature of $175{ }^{\circ} \mathrm{C}$ for 60 minutes.

\section{Test Results}

In the first part, the results from the empirical tests of the bituminous binders are given and the effects of ageing determined by the RTFOT and its modified version $3 x$ RTFOT are described. Next section then provides results from tests performed using the DSR.

\section{Needle Penetration, Softening Point, Elastic Recovery and Resilience}

Table 2 shows the results from needle penetration, softening point, elastic recovery and resilience measurements for individual binders.

Table 2. Basic characteristics before ageing, after RTFOT and 3xRTFOT, for the CRmBs and a paving binder

\begin{tabular}{|c|c|c|c|c|c|}
\hline \multirow{2}{*}{$\begin{array}{l}\text { Rubber } \\
\text { content }\end{array}$} & \multirow{2}{*}{ Ageing } & Needle penetration & Softening point & Elastic recovery & Resilience \\
\hline & & EN 1426 & EN 1427 & EN 13398 & EN 13880-3 \\
\hline$[\%]$ & & {$[0,1 \mathrm{~mm}]$} & {$\left[{ }^{\circ} \mathrm{C}\right]$} & [\%] & [\%] \\
\hline \multirow{3}{*}{0} & - & 57 & 47,4 & - & - \\
\hline & RTFOT & 37 & 52,9 & - & - \\
\hline & $3 \times R T F O T$ & 26 & 59,1 & - & - \\
\hline \multirow{3}{*}{11} & - & 45 & 55,2 & 40,0 & 14,7 \\
\hline & RTFOT & 35 & 60,7 & 65,0 & 18,3 \\
\hline & 3xRTFOT & 27 & 69,4 & 67,0 & 20,3 \\
\hline \multirow{3}{*}{13} & - & 42 & 59,7 & 53,0 & 20,0 \\
\hline & RTFOT & 33 & 66,2 & 69,0 & 22,7 \\
\hline & 3xRTFOT & 25 & 70,3 & 72,0 & 23,3 \\
\hline \multirow{3}{*}{15} & - & 39 & 61,2 & 55,0 & 21,3 \\
\hline & RTFOT & 30 & 67,6 & 72,0 & 25,0 \\
\hline & 3xRTFOT & 24 & 73,1 & 72,5 & 25,7 \\
\hline \multirow{3}{*}{17} & - & 35 & 64,7 & 60,5 & 26,7 \\
\hline & RTFOT & 29 & 69,4 & 72,5 & 27,0 \\
\hline & 3xRTFOT & 23 & 73,5 & 73,0 & 27,3 \\
\hline
\end{tabular}


Figure 3 shows the change in needle penetration during different ageing levels and for different contents of crumb rubber. The paving bitumen 50/70 has the highest penetration and as the content of crumb rubber increases, the binder becomes stiffer. After short-term ageing using the RTFOT, the bituminous binder stiffens significantly and the differences between the individual binders with different contents of crumb rubber are smaller. The lowest values of needle penetration are observed on binders that undergo the triple RTFOT. It is also obvious, that the stiffness of binders with increasing amount of crumb rubber changes least, while the stiffness of the general paving bitumen changes significantly.

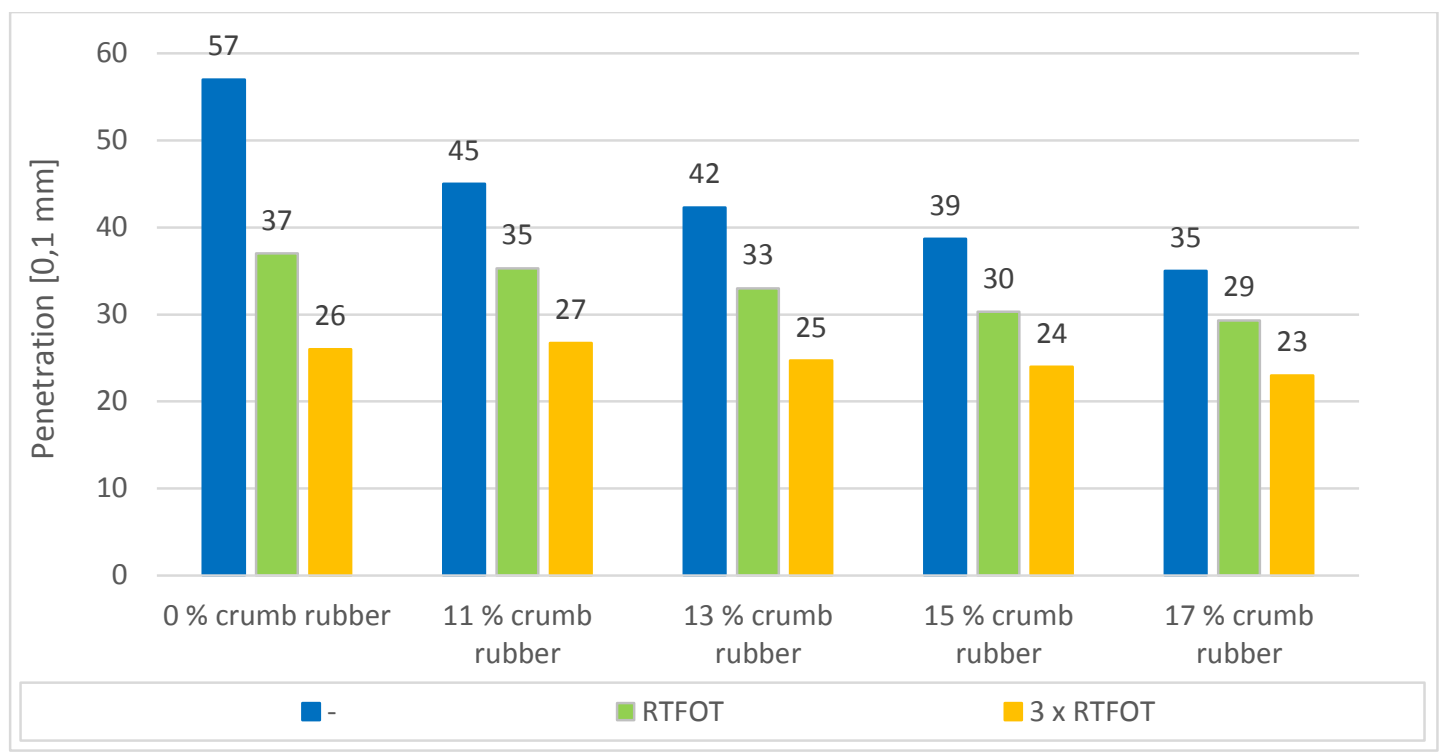

Figure 3. Change in needle penetration for $\mathrm{CRmB}$ and neat bitumen before and after ageing processes using RTFOT and 3xRTFOT

Figure 4 shows the change in softening point depending on the binder ageing and on the crumb rubber content. It can be seen that increase in the amount of crumb rubber increases the value of softening point, which leads to a higher resistance of bitumen mixture against permanent deformation. After binder ageing using RTFOT and $3 \times$ RTFOT procedure, the value of the softening point increases. 


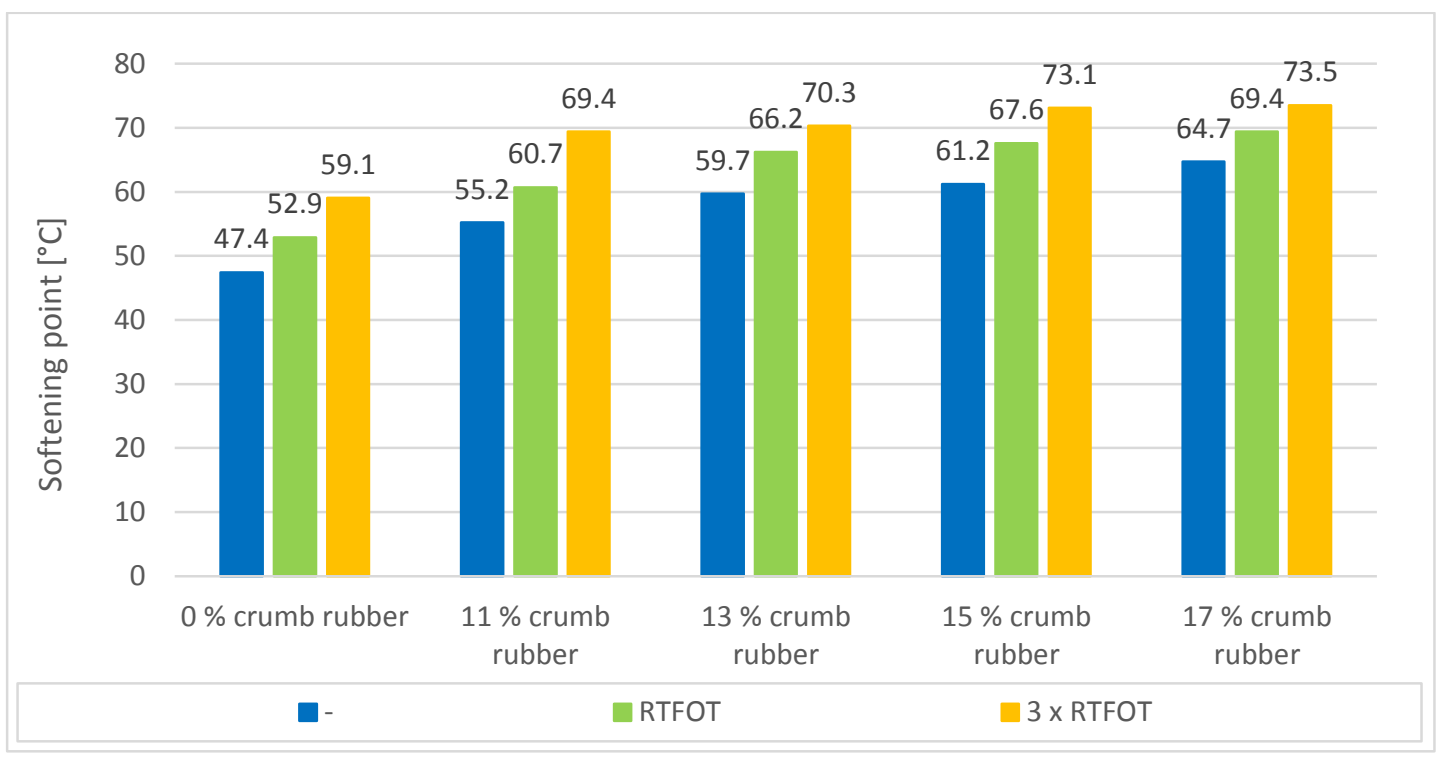

Figure 4. Change in softening point of $\mathrm{CRmB}$ and neat bitumen before and after ageing using RTFOT and 3xRTFOT

Figure 5 describes the change in elastic recovery. The highest elastic recovery was observed in the case of $\mathrm{CRmB}$ with the highest crumb rubber content. This is because rubber has a high elasticity and therefore its higher amount increases the elastic recovery. It is immediately obvious that elastic recovery increases as the crumb rubber content in the binder increases and also the effects of ageing are smaller.

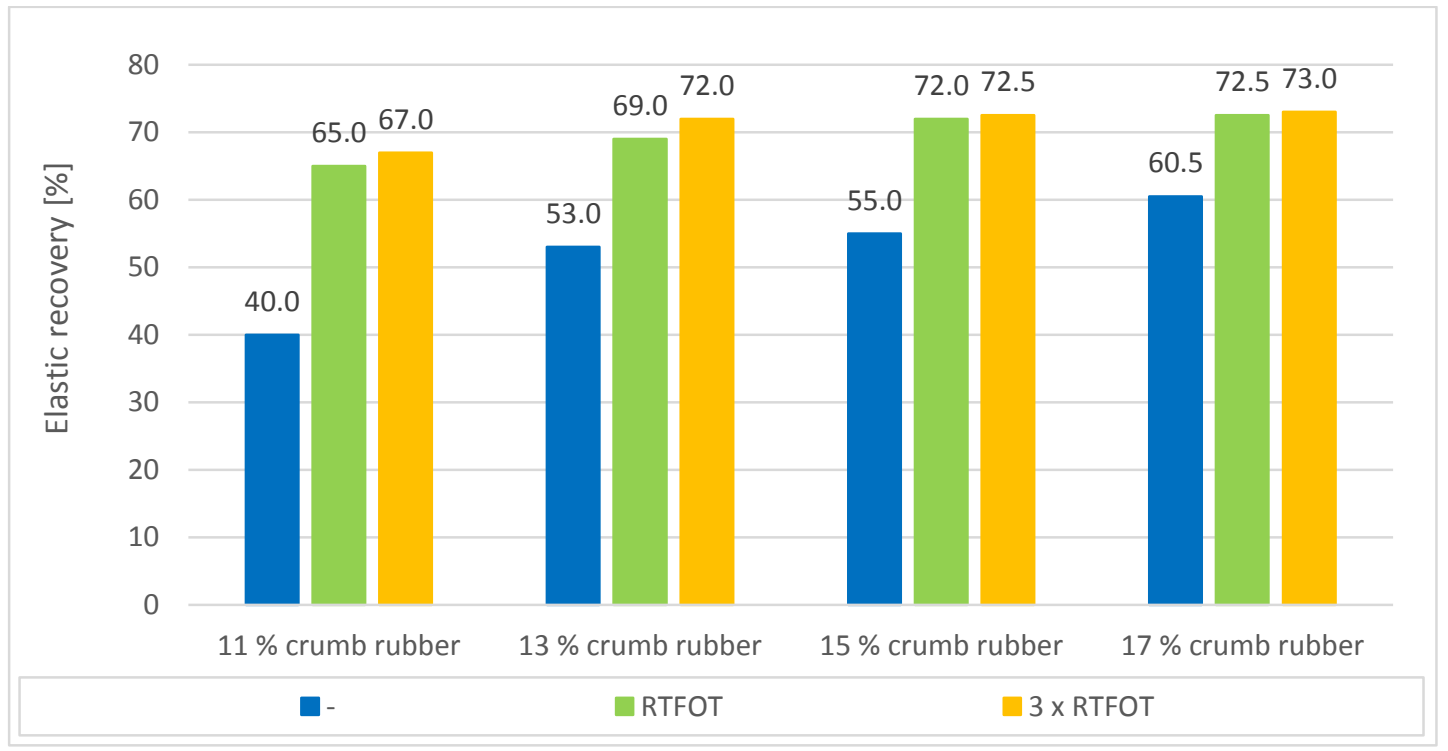

Figure 5. Change in elastic recovery of CRmB after ageing using RTFOT and 3XRTFOT

The test of bituminous binder resilience describes the regeneration during $20 \mathrm{~s}$ at $25^{\circ} \mathrm{C}$ after strain application. For $\mathrm{CRmB}$ this value is higher than for polymer modified bitumens. This result can be explained by the elastic properties of rubber. As shown in Figure 6, increased amount of crumb rubber again contributes to higher 
values of resilience and a crumb rubber content higher than $15 \%$ minimizes the effects of ageing.

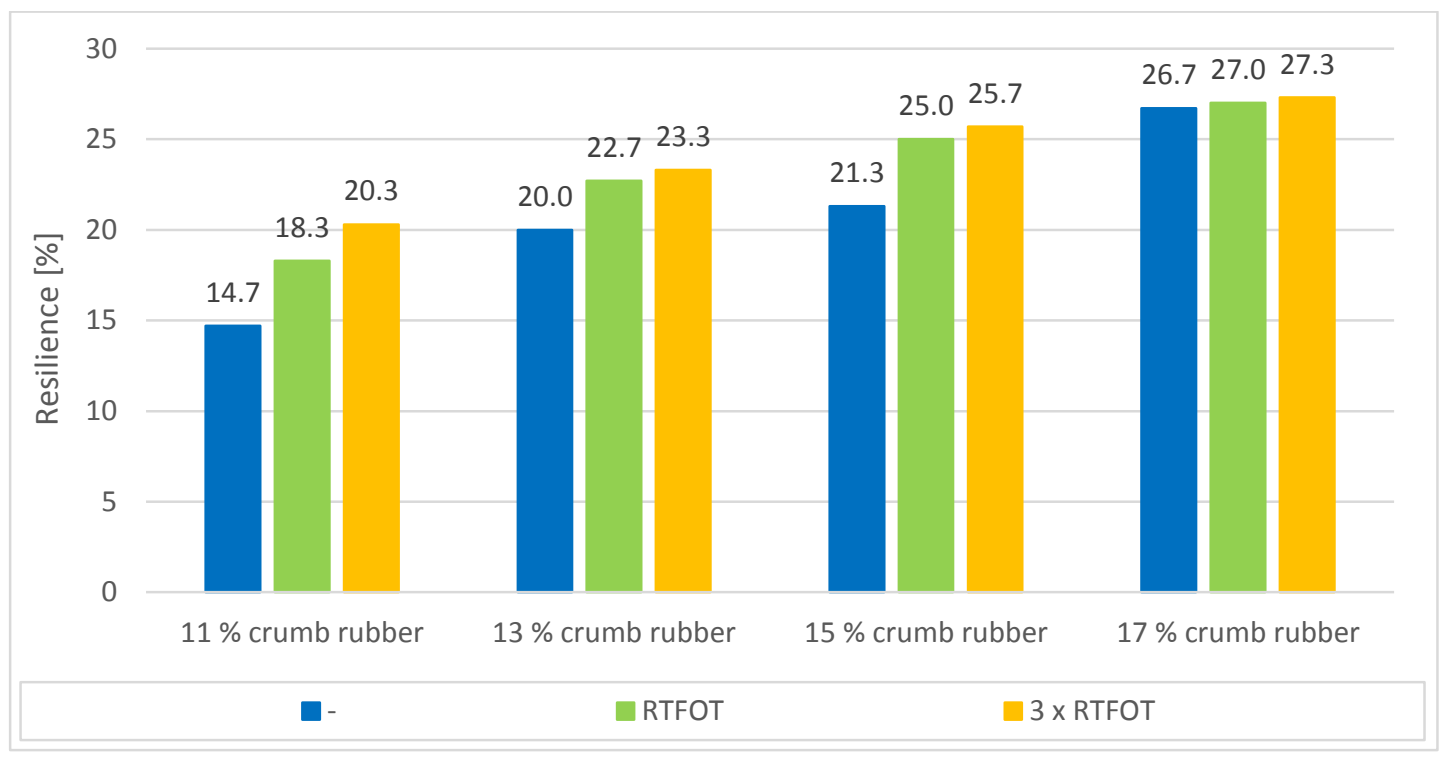

Figure 6. Change in resilience of CRmB after ageing by RTFOT and 3xRTFOT

All the above described tests provide information about binder properties at temperatures of $25^{\circ} \mathrm{C}$ and higher. It is documented that paving binder stiffens during ageing and becomes more brittle, which negatively affects the formation of low temperature cracks, and modification by using crumb rubber significantly reduces this stiffening. This reduction of stiffness of $\mathrm{CRmB}$ can be partially influenced by the digestion of the rubber particles in hot bitumen during long term ageing ( $3 \times$ RTFOT).

\section{Shear Stress Relaxation}

Figure 7 shows the record of shear stress over time as stress relaxation for paving bitumen with a gradation of $50 / 70$ at a temperature of $0{ }^{\circ} \mathrm{C}$. It is obvious that bitumen aged using the RTFOT or $3 \times$ RTFOT has a higher shear stress and higher stiffness during the shear strain application, which has a size of $1 \%$ in all measurements.

Figure 8 shows the record of shear stress over time for paving bitumen and for $\mathrm{CRmB}$ containing $15 \%$ of crumb rubber. The bitumens were tested at $-10{ }^{\circ} \mathrm{C}$ and $0{ }^{\circ} \mathrm{C}$. It can be seen that lowering the temperature to $-10{ }^{\circ} \mathrm{C}$ leads to a much higher stress value. At $0{ }^{\circ} \mathrm{C}$, the stress measured for the paving bitumen is approximately half the value observed in $\mathrm{CRmB}$. However at $-10^{\circ} \mathrm{C}$, the stress for both bitumens is the same. This can be explained by the ageing of bitumen and by lower temperature sensitivity of crumb rubber. 


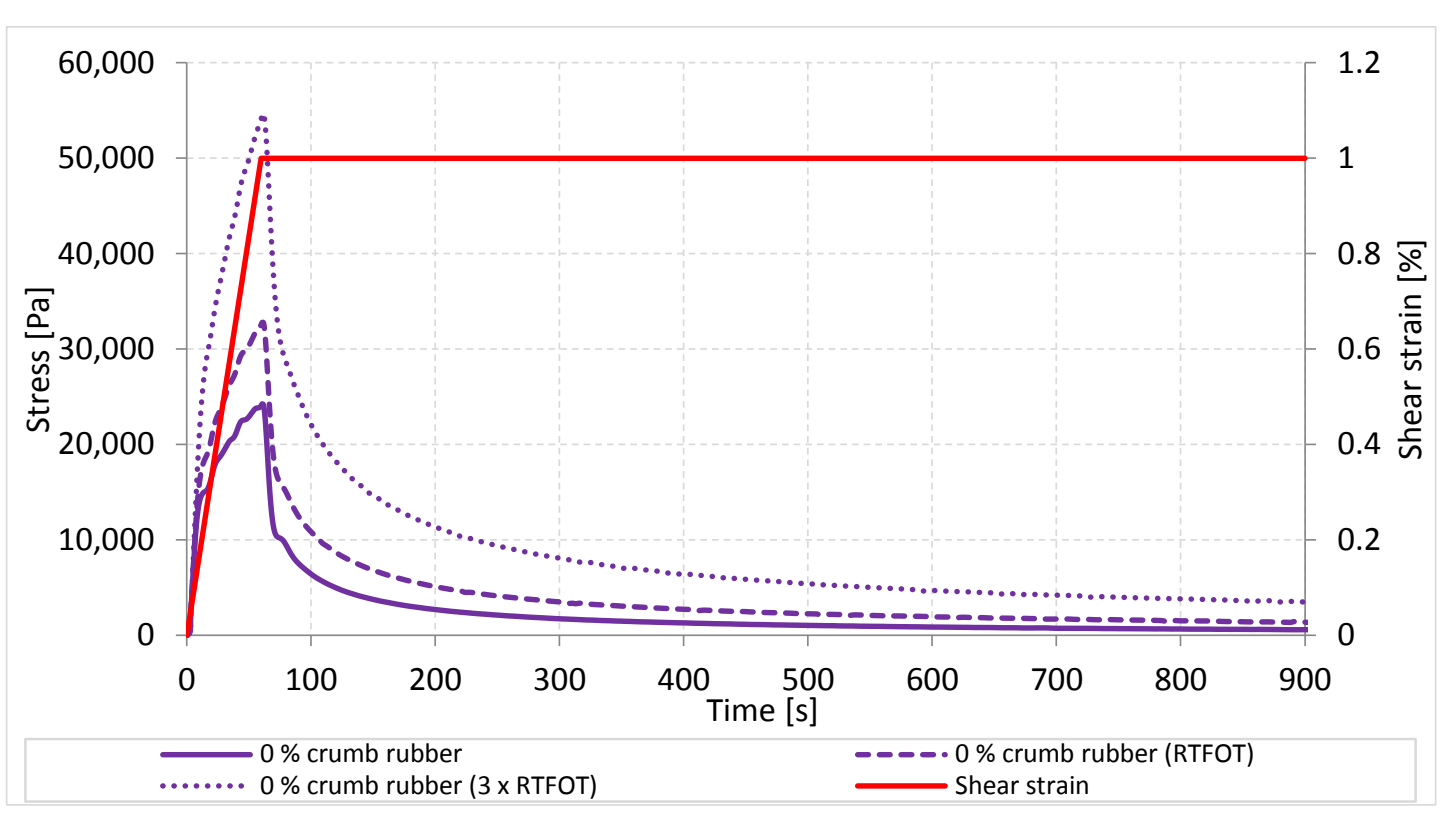

Figure 7. The record of shear stress relaxation test at $0{ }^{\circ} \mathrm{C}$ of neat paving bitumen before and after RTFOT and 3xRTFOT ageing

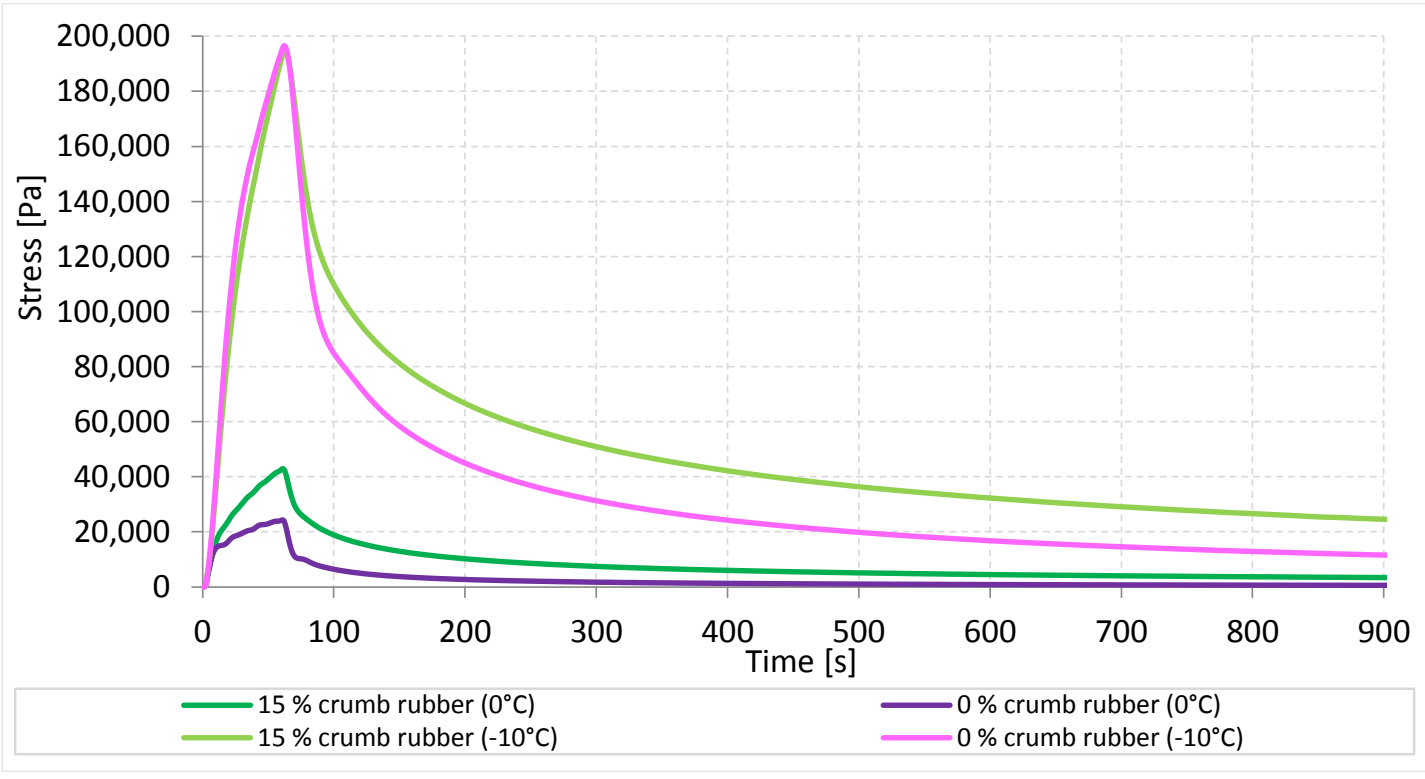

Figure 8. The record of shear stress relaxation test at $-10{ }^{\circ} \mathrm{C}$ and $0{ }^{\circ} \mathrm{C}$ for neat bitumen and $\mathrm{CRmB}$ with $15 \%$ crumb rubber content

Figure 9 shows residual stress dependence (complementary to stress relaxation) on relaxation time. Initial shear stress was standardized to a value of $100 \%$. It is obvious, that as the temperature decreases and crumb rubber content increases, the decrease of stress slows down, i.e. the rate of shear stress relaxation decreases. Bitumen ageing also decreases stress relaxation, but ageing of $\mathrm{CRmB}$ has almost no effect at $-10^{\circ} \mathrm{C}$.

To make it more clear, a relaxation time of $15 \mathrm{~s}$ and $900 \mathrm{~s}$ was chosen and results are summarized in bar chart graphs that represent the decrease of stress by the value of 
shear stress (see Figure 10 and Figure 11). Results emphasize the effects of ageing of paving bitumen on relaxation during both temperatures tested and how the effects of ageing decrease as the content of crumb rubber content increases, when the crumb rubber content in $\mathrm{CRmB}$ reaches $13 \%$, the properties are basically identical.

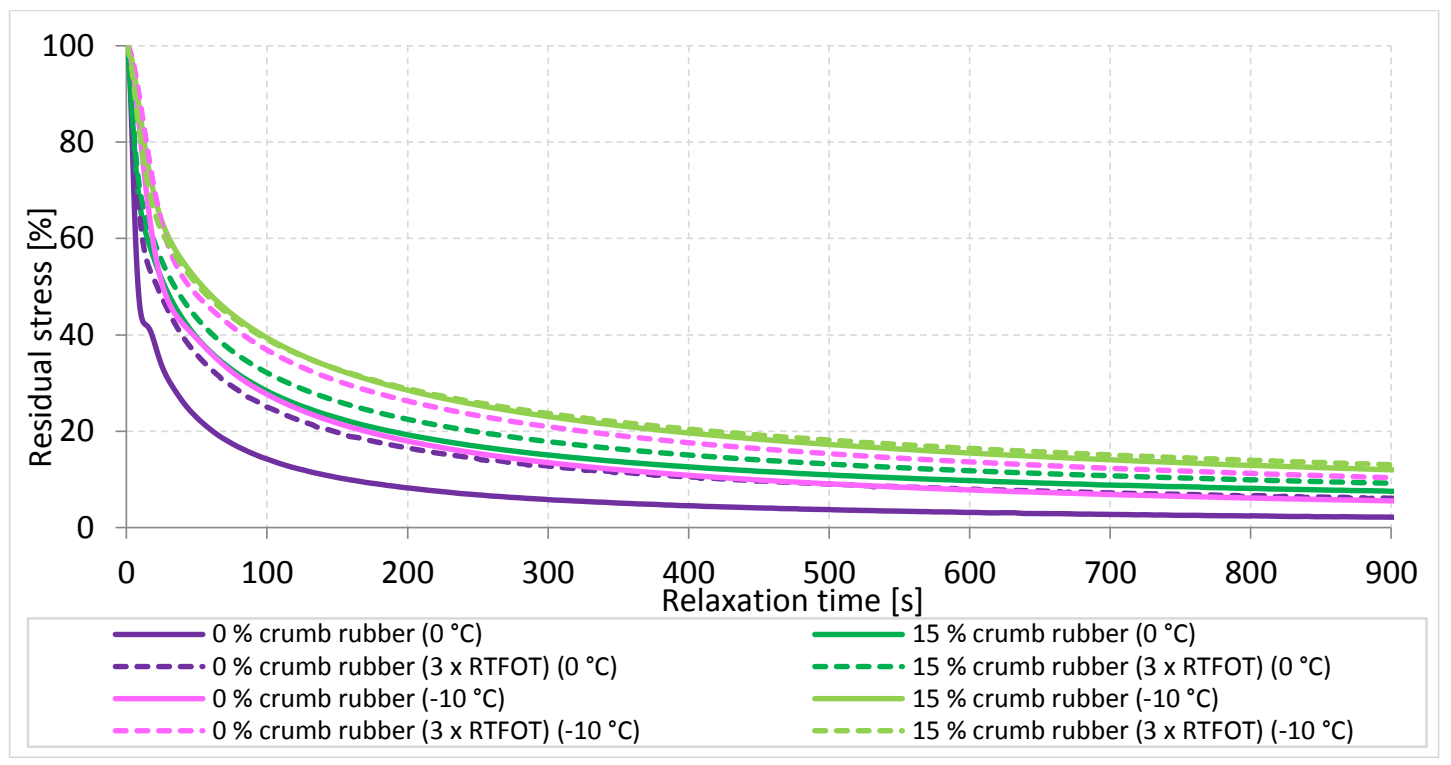

Figure 9. Decrease of stress for neat bitumen and CRmB $15 \%$ depending on ageing and temperature

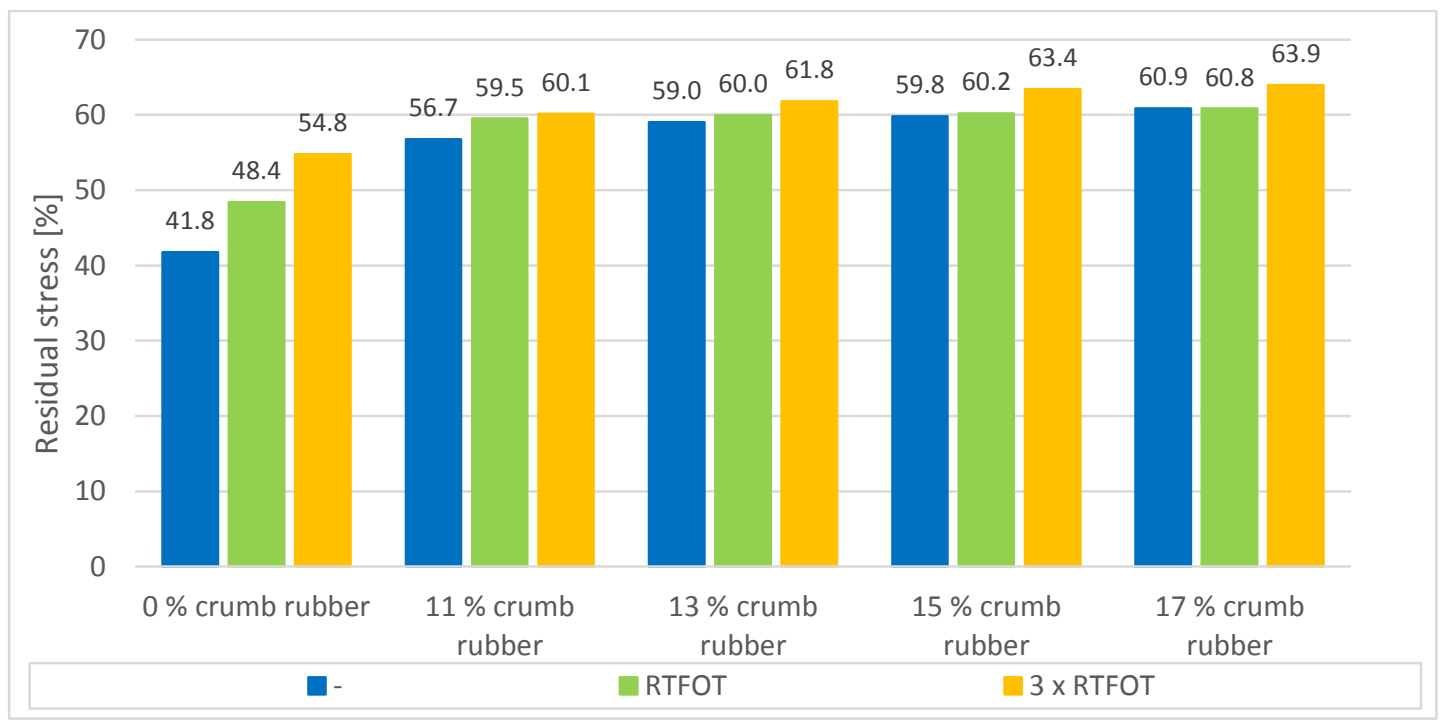

Figure 10. Decrease of stress at time $t=15 \mathrm{~s}$ and temperature of $0{ }^{\circ} \mathrm{C}$, depending on the crumb rubber content and binder ageing 


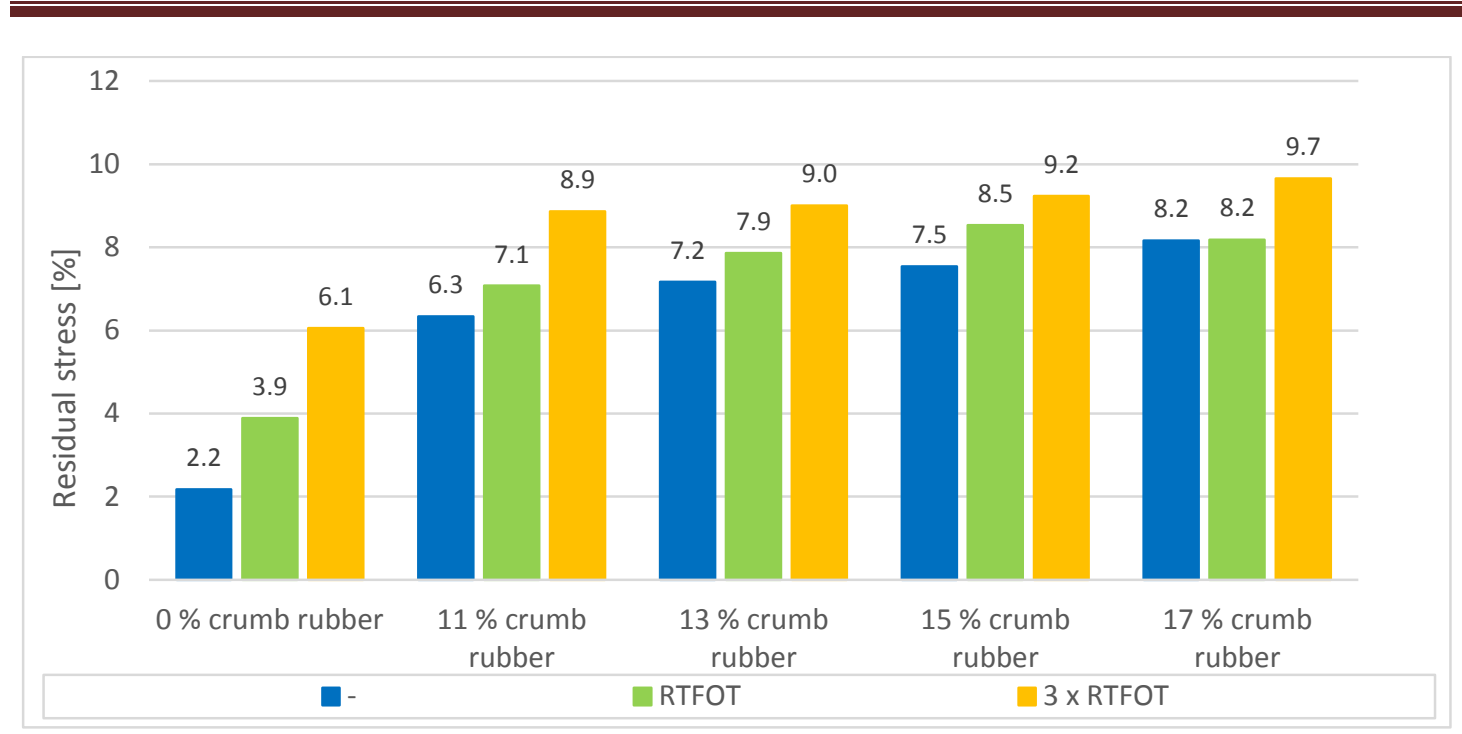

Figure 11. Decrease of stress at time $t=900 \mathrm{~s}$ and temperature of $0{ }^{\circ} \mathrm{C}$, depending on the crumb rubber content and binder ageing

Figure 12 shows the dependency of residual shear stress on temperature for the relaxation time of $15 \mathrm{~s}$ for paving bitumen and $\mathrm{CRmB}$ with $15 \%$ crumb rubber content. It can be seen that there is a stronger dependency of stiffness on temperature in the case of paving bitumen, because the curve representing the reduction of relaxation with increasing temperature, rises faster than in the case of CRmB.

Figure 13 represents the slope of the line of stress reduction with increasing temperature for all tested binders. This slope of the line is given by the tangent of the angle between the curves described in Figure 12 and the horizontal axis. The smaller the magnitude of the slope, the more suitable is the binder for designing mixtures that resist crack formation, because the critical stress, which causes disruption of the tested specimen by a crack, is reached at a lower temperature.

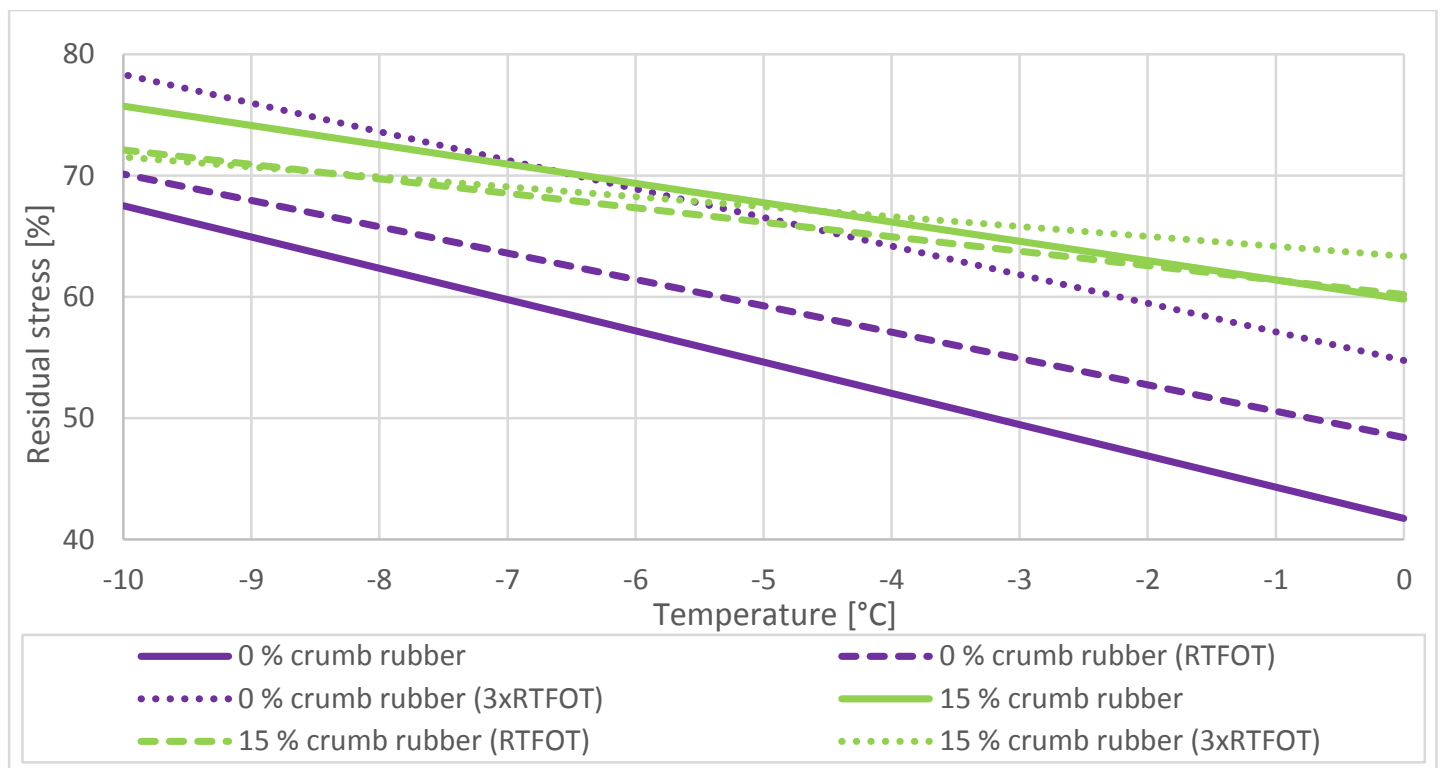

Figure 12. Dependency of stress decrease at time $t=15 \mathrm{~s}$ on temperature 


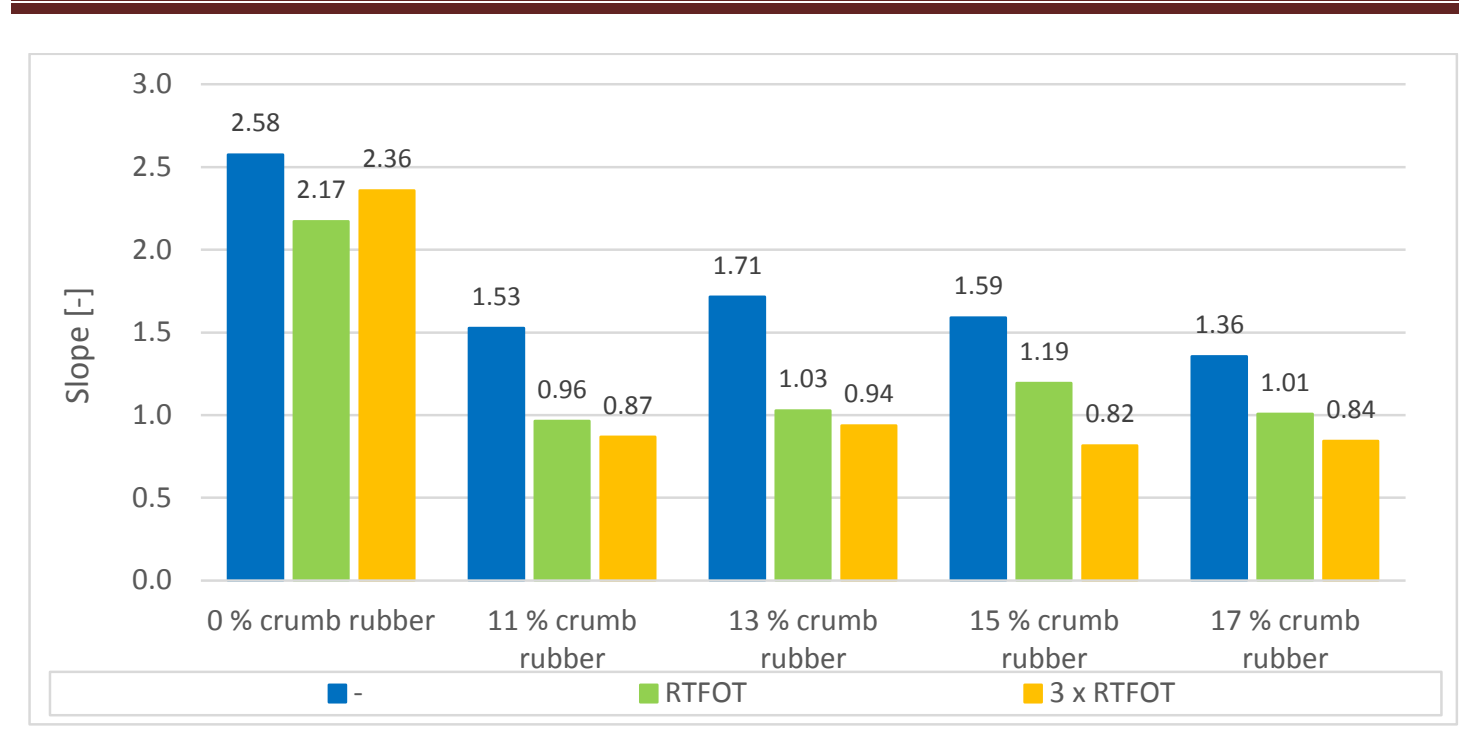

Figure 13. Size of the slope of the line of various binders during a temperature change from $-10{ }^{\circ} \mathrm{C}$ to $0{ }^{\circ} \mathrm{C}$

This confirms the results of the measurements of low temperature properties of bitumen binders obtained from the TSRST (see Figure 1). At temperatures lower than $-10^{\circ} \mathrm{C}$, the paving bitumen will have worse low temperature properties than $\mathrm{CRmB}$ and a crack will form sooner (at a relatively higher temperature).

Some fluctuations in the results obtained using CRmBs with different crumb rubber content prove the effects of the heterogeneity of CRmB samples, especially the results from testing at lower temperatures are slightly variable, and it is necessary to make several measurements, where anomalies are eliminated and an average from at least 3 measurements is taken.

\section{Conclusion}

The reduction of crack formation on asphalt pavements during freezing is a serious issue in harsh climate conditions of countries in Central and Eastern Europe.

Various tests of bituminous mixtures are used to describe their resistance to cracks, for example the TSRST according to the EN 12697-46 and relaxation of bending stress at $0{ }^{\circ} \mathrm{C}$. These, however, are time-consuming tests and also depend on the particular mixture characteristics (aggregate gradation, air void content, type of the binder, binder content etc.) and it is not possible to reliably determine the effects of bitumen binder type on crack formation.

The article focuses on binder tests at low temperatures, including the effects of binder ageing. Penetration, softening point, elastic recovery and resilience were determined on a set of bituminous binders consisting of paving bitumen and crumb rubber modified bitumens $(\mathrm{CRmB})$, always for the original bitumen, after short-term ageing RTFOT (75 minutes) and long-term ageing RTFOT (225 minutes). None of these tests was able to determine the behaviour of bitumens at low temperatures, and only based on the results of the ageing tests it was possible to predict questionable behaviour of binder. 
Measuring low temperature properties using dynamic shear rheometer (DSR) proved to be much more reliable. A test of shear stress relaxation at temperatures of $0{ }^{\circ} \mathrm{C}$ and $-10{ }^{\circ} \mathrm{C}$ was chosen, using parallel measuring plates with a diameter of $8 \mathrm{~mm}$ and gap size $2 \mathrm{~mm}$. These temperature points were selected with respect to the possible measuring range of DSR and were derived from the measurements of low temperature properties of bitumen mixtures using TSRST. Relaxation tests were performed in the controlled strain regime. Shear strain (rotation of upper geometry) was set to $1 \%$ of the sample thickness and stress was applied for $60 \mathrm{~s}$. Relaxation time was set to a period of 15 minutes.

Binder tests, especially after the accelerated ageing simulation, were able to well differentiate between the behaviour of paving bitumen and bitumens with various crumb rubber content. A well-known practical experience that $\mathrm{CRmB}$ with crumb rubber content of $15 \%$ provides suitable binder properties, reduces ageing and exhibits improved low temperature behaviour, was proved.

CRmBs could be a good alternative to polymer modified bitumens. In the Czech Republic, CRmBs are often used for stress absorbing layers (SAL), to overlay broken Portland cement concrete pavements or to overlay cracked bituminous layers with a thickness of $25 \mathrm{~mm}$ to $30 \mathrm{~mm}$.

\section{Acknowledgement}

The article has been prepared with the support of TA03030381 Project "New Test Methods for Bituminous Binders and Mixtures to Allow for Extension of Service Lifetime of Flexible Pavements" and financial aid from the EU under "OP Research and Development for Innovation, Project ID No. CZ.1.05/2.1.00/03.0097, within the activities of the Regional Centre AdMaS "Advanced Construction Materials, Structures, and Technologies".

\section{References}

Bahia, H. U., Anderson, D. A. (1995). "The Pressure Aging Vessel (PAV): a Test to Simulate Rheological Changes Due to Field Aging," Physical Properties of Asphalt Cement Binders, pp. 67-88.

Bahia, H. U., Hislop, W. P., Zhai, H., Rangel, A. (1998). "Classification of Asphalt Binders into Simple and Complex Binders," Journal of the Association of Asphalt Paving Technologists, pp. 67.

Brown, S.F., Scholz, T.V. (2000). "Development of Laboratory Protocols for the Ageing of Asphalt Mixtures," $2^{\text {nd }}$ Eurasphalt \& Eurobitume Congress Barcelona.

Carlson, D.D., Zhu, H. (1999). "Asphalt-Rubber an Anchor to Crumb Rubber Markets," Third Joint UNCAD/IRSG Workshop on Rubber and the Environment, International Rubber Forum, Veracruz.

European Standard (2007). "EN 12607-1 Bitumen and bituminous binders Determination of the resistance to hardening under the influence of heat and air Part 1: RTFOT method." 
European Standard (2007). "EN 1426 Bitumen and bituminous binders Determination of needle penetration."

European Standard (2007). "EN 1427 Bitumen and bituminous binders Determination of the softening point - Ring and Ball method."

European Standard (2010). "EN 13302 Bitumen and bituminous binders Determination of dynamic viscosity of bituminous binder using a rotating spindle apparatus."

European Standard (2010). "EN 13398 Bitumen and bituminous binders Determination of the elastic recovery of modified bitumen."

European Standard (2010). "EN 13880-3 Hot applied joints sealants - Part 3: Test method for the determination of penetration and recovery (resilience)."

European Standard (2010). "EN 14770 Bitumen and bituminous binders Determination of complex shear modulus and phase angle - Dynamic Shear Rheometer (DSR)."

European Standard (2012). "EN 12697-46 Bituminous mixtures - Test methods for hot mix asphalt - Part 46: Low temperature cracking and properties by uniaxial tension tests."

Gauer, P. (1996). "Relaxationsverhalten von Asphalt bei tiefen Temperaturen," Eurasphalt \& Eurobitume Congress, Strasbourg.

Heitzman, M. A. (1992). "State of the Practice - Design and Construction of Asphalt Paving Materials with Crumb Rubber Modifier," FHWA-SA-92-022, Federal Highway Administration.

Isacsson, U., Zeng, H. (1998). "Low-temperature Cracking of Polymer-modified Asphalt, Materials and Structures,” p. 58-63.

Kudrna, J., Dasek, O. (2012). "European Approach to Asphalt Rubber," Asphalt Rubber Conference 2012, Munich.

McGennis, R.B., Shuler, S., Bahia, H.U. (1994). "Background of Superpave Asphalt Binder Test Methods," FHWA-SA-94-069, National Asphalt Training Center, Demonstration Project 101, Washington, DC.

Mezger, T.G. (2011). "The Rheology Handbook. For users of rotational and oscillatory rheometers. 3rd revised edition," ISBN 978-3-86630-864-0, Germany.

Mturi, G.A.J., O’Connell, J. (2012). "Monitoring Ageing of Bituminous Binders," 31st Annual Southern African Transport Conference, Pretoria.

Muller, J., Jenkins, K.J. (2011). "The Use of an Extended Rolling Thin Film Ageing Method as an Alternative to the Pressurised Ageing Vessel Method in the 
Determination of Bitumen Durability, $10^{\text {th }}$ Conference on Asphalt Pavements for Suothern Africa, KwaZulu-Natal.

Sebaaly, P.E., Lake, A., Epps, J. (2001). "Evaluation of Low Temperature properties of HMA Mixtures," ASCE Journal of Transportation Engineering.

Spiegl, M. (2009). "Entwicklungen von gebrauchsverhaltensorientierten Bitumenspezifikationen," Bauseminar Gestrata.

Sui, Ch., Farrar, M.J, Harnsberger, P.M., Tuminello, W.H., Turner, T.F. (2011). "New Low-Temperature Performance-Grading Method," Transportation Research Record 2207, p. 43-48.

Technical Recommendation (2010). "TP 151 High stiffness mixtures. Ministry of Transport."

Zalman, L. (2011). "Dynamic viscosity of bituminous binders and additives," Conference Asphalt Pavements, p. 4. Czech Republic. 